time T0, previous to the first Al therapy, and after 12 months (time T1). REMS scan only was repeated also at 18 months (T2), since a 6-month interval between two consecutive scans is not recommended for DXA. The bone mineral density (BMD) was measured with both techniques.

Results: Overall, 254 ER+ BC patients were enrolled (127 per group). The effect of denosumab on BMD is reported in Table. The BMD values obtained by DXA and REMS were not significantly different at T0 and T1, whereas the difference between Group A and B at T1 was statistically significant $(p<0.001)$ both for REMS and DXA. At T2, REMS confirmed the increasing trend of BMD for Group $A$ and the decreasing one for Group B, and the difference between groups was statistically significant $(p<0.001)$. For each time point and each group, there were not statistically significant differences between DXA and REMS.

Conclusion: Several studies have shown the effect of denosumab on BMD over a period not less than 2 years from the start of treatment. This study showed the feasibility of short-term follow-up using REMS lumbar spine scans at 6-month time steps.

References:

[1] Diez-Perez A et al, Aging Clin Exp Res 2019;31(10):1375-89

[2] Di Paola M et al, Osteoporos Int 2018;30:391-402

Table 1. BMD values, expressed as $\mathrm{g} / \mathrm{cm}^{2}$, measured by DXA and REMS for Group A (patients receiving Als only) and Group B (patients receiving Als and denosumab) at baseline (T0), 12 months (T1) and 18 months (T2) from the start of therapy. Results are presented as median values with $25^{\text {th }}$ and $75^{\text {th }}$ percentiles. P-values are obtained with a Mann-Whitney test.

\begin{tabular}{|c|c|c|c|c|c|c|}
\hline \multirow[b]{2}{*}{ Scan time } & \multicolumn{3}{|c|}{ DXA } & \multicolumn{3}{|c|}{ REMS } \\
\hline & Group A & Group B & $p$ & Group A & Group B & $p$ \\
\hline TO & $\begin{array}{c}0.840 \\
(0.719-0.959)\end{array}$ & $\begin{array}{c}0.867 \\
(0.723-0.958)\end{array}$ & 0.99 & $\begin{array}{c}0.833 \\
(0.708-0.949)\end{array}$ & $\begin{array}{c}0.855 \\
(0.714-0.973)\end{array}$ & 0.77 \\
\hline$T 1$ & $\begin{array}{c}0.823 \\
(0.702-0.944)\end{array}$ & $\begin{array}{c}0.889 \\
(0.749-0.990)\end{array}$ & 0.003 & $\begin{array}{c}0.819 \\
(0.691-0.927)\end{array}$ & $\begin{array}{c}0.887 \\
(0.740-1.018)\end{array}$ & $<0.001$ \\
\hline$T 2$ & - & - & - & $\begin{array}{c}0.801 \\
(0.679-0.909)\end{array}$ & $\begin{array}{c}0.899 \\
(0.754-1.020)\end{array}$ & $<0.001$ \\
\hline
\end{tabular}

Note: The authors D. Ciardo, M. Ciccarese, F. Conversano, M. Di Paola, R. Forcignanò, A. Grimaldi, F.A. Lombardi, M. Muratore and P. Pisani are listed in alphabetical order

Disclosure of Interests: None declared

DOI: 10.1136/annrheumdis-2020-eular.3806

\section{SAT0462 1 ASSESSMENT OF BONE MINERAL DENSITY IN INFLAMMATORY BOWEL DISEASE}

C. Daldoul ${ }^{1}$, N. El Amri ${ }^{1}$, K. Baccouche ${ }^{1}$, H. Zeglaoui ${ }^{1}$, E. Bouajina ${ }^{1} .{ }^{1}$ Farhat Hached Hospital, Rheumatology, Sousse, Tunisia

Background: Inflammatory bowel disease (IBD), including ulcerative colitis (UC) and Crohn's disease (CD), is considered as a risk factor of low bone mineral density (BMD). In fact, the prevalence of osteoporosis ranges from $17 \%$ to $41 \%$ in IBD patients. The possible contributing factors may include malabsorption, glucocorticoid treatment and coexisting comorbidities

Objectives: The purpose of our work was to determine the frequency and the determinants of osteoporosis in patients with IBD and to assess whether there is a difference in BMD status between UC and CD.

Methods: This is a retrospective study, over a period of 5 years (from January 2014 to December 2018) and including patients followed for IBD who had a measurement of BMD by DEXA. Clinical, anthropometric and densitometric data (BMD at the femoral and vertebral site) were recorded. The WHO criteria for the definition of osteoporosis and osteopenia were applied.

Results: One hundred and five patients were collected; among them 45 were men and 60 were women. The average age was 45.89 years old. The average body mass index (BMI) was $25.81 \mathrm{~kg} / \mathrm{m} 2$ [16.44-44.15]. CD and UC were diagnosed in respectively $57.1 \%$ and $42.9 \%$. A personal history of fragility fracture was noted in $4.8 \%$. Hypothyroidism was associated in one case. Early menopause was recorded in $7.6 \% .46 .8 \%$ patients were treated with corticosteroids. The mean BMD at the vertebral site was $1.023 \mathrm{~g} / \mathrm{cm} 3[0.569-1.489 \mathrm{~g} /$ $\mathrm{cm} 3$ ]. Mean BMD at the femoral site was $0.920 \mathrm{~g} / \mathrm{cm} 3[0.553-1.286 \mathrm{~g} / \mathrm{cm} 3$ ]. The mean T-score at the femoral site and the vertebral site were -1.04 SD and $-1.27 \mathrm{SD}$, respectively. Osteoporosis was found in $25.7 \%$ and osteopenia in $37.1 \%$. Osteoporosis among CD and UC patients was found in respectively $63 \%$ and $37 \%$. The age of the osteoporotic patients was significantly higher compared to those who were not osteoporotic ( 52.23 vs 43.67 years, $p=0.01$ ).
We found a significantly higher percentage of osteoporosis among men compared to women $(35.6 \%$ vs $18.3 \%, p=0.046)$. The $B M I$ was significantly lower in the osteoporotic patients (23.87 vs $26.48 \mathrm{~kg} / \mathrm{m} 2, \mathrm{p}=0.035)$ and we found a significant correlation between BMI and BMD at the femoral site $(p=0.01)$. No increase in the frequency of osteoporosis was noted in patients treated with corticosteroids $(27.9 \%$ vs $21.6 \%, p=0.479)$. Comparing the UC and CD patients, no difference was found in baseline characteristics, use of steroids or history of fracture. No statistically significant difference was found between UC and CD patients for osteoporosis $(p=0.478), B M D$ at the femoral site $(p=0.529)$ and at the vertebral site $(p=0.568)$.

Conclusion: Osteoporosis was found in $25.7 \%$ of IBD patients without any difference between CD and UC. This decline does not seem to be related to the treatment with corticosteroids but rather to the disease itself. Hence the interest of an early screening of this silent disease.

Disclosure of Interests: None declared

DOI: 10.1136/annrheumdis-2020-eular.6007

\section{SAT0463 SEVERE OSTEOPOROSIS IN COLOMBIAN PATIENTS WITH SYSTEMIC LUPUS ERYTHEMATOSUS}

J. C. Diaz-Coronado $^{1,2}$, S. Herrera ${ }^{1}$, D. Hernandez-Parra ${ }^{1}$, L. Betancur-

Vasquez $^{2}$, D. Gonzalez-Hurtado ${ }^{2}$, J. Gonzalez-Arango ${ }^{2}$, L. Uribe-Arango ${ }^{2}$, M. F. Saavedra Chacón ${ }^{2}$, J. Lacouture-Fierro ${ }^{2}$, S. Guerra-Zarama ${ }^{2}$, S. Monsalve ${ }^{2}$, J. D. Serna Giraldo ${ }^{2}$, J. D. Serna ${ }^{2}$, J. Barbosa ${ }^{2}$, R. Pineda Tamayo ${ }^{1} .{ }^{1}$ Artmedica, Grupo de Información Clínica, Medellín, Colombia; ${ }^{2}$ CES University,

Departamento Medicina Interna, Medellín, Colombia

Background: Osteoporosis predominantly affects post-menopausal women There is an important percentage of the population that have additional risk factors that decrease bone mineral density. Patients with Systemic Lupus Erythematosus (SLE) have an increased risk for osteoporosis due to corticosteroid use and chronic inflammation. This population could have a higher prevalence of osteoporosis when compared to post-menopausal women of equal or older age. There is a paucity of information regarding bone mineral density and SLE in Latin America.

Objectives: To describe the prevalence and incidence of osteoporosis and osteoporotic fractures in a Colombian population with Systemic Lupus Erythematosus Methods: We collected 464 clinical records of patients who met either the American College of Rheumatology 1997 or Systemic Lupus International Collaborating Clinics (SLICC) 2012 classification criteria for systemic lupus erythematosus between January 2015 and June 2019. The clinical and immunoserological characteristics, and damage accrual were monitored for one year. The diagnosis of osteoporosis was confirmed with densitometry by energy $x$-ray absorptiometry (DXA) and the presence of fragility fractures according to the rheumatologist's report in the clinical history. The description of proportions and incidence rate of osteoporosis and fragility fracture is performed.

Results: The mean age was 45 years, $96.5 \%$ were women and the mean disease duration was 12 years. Others clinical characteristics in table 1 . The prevalence of osteoporosis was $13.8 \%$ with an incidence of 1.1 fractures / 100 person-months in the general population with SLE. In postmenopausal women, over 50 years the prevalence of osteoporosis was $28.4 \%$ with an incidence of 0.8 fractures / 100 months person. In the densitometric characteristics, the mean bone mineral density was $0.772 \mathrm{gr} / \mathrm{cm} 2$, T-score spine -2.9 and T-score femoral -2.6. SLEDAI mean 1.5 (SD 2.92) and SLICC mean 1.

Table 1. clinical characteristics

\begin{tabular}{lcc}
\hline & $\mathbf{n}$ & $\%$ \\
\hline Active Smoking & 83 & 17.9 \\
Premature gonadal failure & 8 & 1.7 \\
Lupic Nephritis & 178 & 38.4 \\
Proteinuria >2.5grams/24hours & 34 & 7.3 \\
End Stage Renal Disease & 16 & 3.4 \\
Anti-dsDNA & 146 & 31.4 \\
Anti-Sm & 110 & 23.7 \\
Anti-Ro & 138 & 29.7 \\
Prednisone Cumulative Dose & $2.8 \mathrm{gr}$ & 12 \\
Antimalarial & 57 &
\end{tabular}

Conclusion: Low bone mineral density and severe osteoporosis are prevalent in our cohort with SLE. We have found a fracture rate of 1080 per 100.000 people, which is well over what has been reported in the general population (53-443 per 100.000 people in women). Osteoporotic fractures are part of damage accrual 